\title{
Online Public Services Usage and the Elderly: Assessing Determinants of Technology Readiness in Japan and the UK
}

\author{
Kunio Shirahada ${ }^{\mathrm{a} *}$, Bach, Quang $\mathrm{Ho}^{\mathrm{b}}$, and Alan Wilson ${ }^{\mathrm{c}}$ \\ ${ }^{a}$ School of Knowledge Science, Japan Advanced Institute of Science and Technology, \\ Ishikawa, Japan; ${ }^{b}$ Research into Artifacts, Center for Engineering (RACE), University of \\ Tokyo, Kashiwa, Japan; 'Department of Marketing, University of Strathclyde Business \\ School, Glasgow, UK
}

Kunio Shirahada is an associate professor in Japan Advanced Institute of Science and Technology. He received his $\mathrm{PhD}$ of technology management at the University of Tokyo in 2009. His research interests include R\&D management, service management, and innovative organization design. He has published in various journals including Technological Forecasting and Social Change, Journal of Business Research, Int. J of Technology Management, Int. J of Automotive Technology Management, Int. J of Innovation and Technology Management.

Bach Ho is a post-doctoral researcher in the University of Tokyo, Japan. His research interests include service hospitality, social services for the elderly, and management of self-service technology. He received his PhD at Japan Advanced Institute of Science and Technology in 2017.

Alan Wilson is Professor of Marketing at Strathclyde University Business School, Scotland, UK. His research focuses on the critical role that both actual and virtual service delivery has on the development of corporate reputation, service differentiation, customer experience management with public and private service organisations. He is the author of several books and has published widely in marketing, service management and technology journals. 


\section{Online Public Services Usage and the Elderly: Assessing Determinants of Technology Readiness in Japan and the UK}

The aim of this study is to identify the impact of the personal beliefs of the elderly on their attitude toward using online public services. To test hypotheses regarding the determinants and background of technology readiness, questionnaires were administered to the elderly in Japan and in the UK, countries with a well-developed online public services infrastructure and an aging population. After structural equation modelling analysis, the research identified that aging satisfaction is the strongest factor in terms of influencing online public services usage, and this is developed through social interaction. Additionally, the research identified similarities and differences stemming from the cultural background of the respondents regarding their fear of using ICT. Our findings contribute to an understanding of the elderly's personal beliefs in terms of online technology usage and relevant social support, which may pave the way for determining an elderlyfriendly social policy for diffusing new technology and services.

Keywords: technology readiness; online public services; structural equation modelling analysis; the elderly; Japan; UK

\section{Introduction}

Governments worldwide are seeking to use information technology to improve service delivery and encourage greater citizen participation [1]. Public services delivered through the Internet have the potential to improve the quality of social welfare by increasing awareness of the services that are available and matching these services with the people who need them [e.g. 2-4]. This indicates how Internet based service technology can contribute to supporting the development of a strong society [5]. However, the capability of citizens to access online public services may not be equal, even if information technology continues to increase in availability. Governments of 
developed countries face a challenging social policy issue brought on by an increasingly aged population that requires the adaption of complex technologies for people who may only have a weak capability to access and use the Internet. There has been little empirical research focused on elderly people as users of online public services, even though the elderly are understood to be less inclined to use such technologies [6]. The aim of this study is to gain insight into Internet based technology and its implications for social policy regarding the elderly by focusing on online public services usage by elderly people in Japan and the UK. Both countries are putting major investment into e-government and e-participation, at the same time as witnessing a growing aged population. In addition, the proportion of older people is increasing in all developed countries and therefore the challenges that this brings can no longer be viewed as a national problem but as a shared issue that needs to be tackled worldwide [7]. This study therefore compares the two countries and investigates how the personal and social characteristics of elderly people affect their propensity to use the Internet by considering the technology readiness index [8] and actual usage of online public services. Technology readiness has been recognized as a factor in promoting behavioural intention toward high-tech products or services, the question of the impact of technology readiness on elderly people's behavioural intention toward online public services requires exploration. The study also considers the most appropriate ways to improve the elderly's intention to use ICT as well as the social policy implications.

This paper is structured in six sections. In section 2, the authors explain the nature of online public services in both Japan and the UK. After that, in section 3, the hypotheses for testing are set by summarizing previous related studies. In section 4 , the details of questionnaires administered in both Japan and the UK as part of an international 
research collaboration are presented. The results are discussed in section 5 , and the authors close with a brief summary incorporating implications for social policy in section 6.

\section{Online public services in Japan and the UK}

According to a recent UN e-government survey [9], there has been a sharp rise in the number of countries that are providing public services online through one-stop platforms. As of 2016, 90 countries offer one or more single-entry portals on public information and/or online services, and 148 countries provide at least one form of online transactional service. In addition, more countries are making an effort through e-government to ensure that public institutions are more inclusive, effective, accountable, and transparent.

The UN categorizes the trends in online public services into two indices: egovernment development and e-participation [9]. The e-government development focuses on the provision of online services, telecommunication connectivity, and human capacity. The e-participation consists of three categories. The first, e-information, means enabling participation by providing citizens with public information and access to on-demand information. The second, e-consultation, is to engage citizens in contributions to and deliberation on public policies and services. The third, e-decision-making, empowers citizens through the co-design of policy options and the co-production of service components and delivery modalities. UN e-government survey also says "while developed countries, especially European countries, are among the top 50 performers, many developing countries - especially lower-middle income countries - are making good progress" [9, p.3]. Regarding the e-government development scores in 2016, Japan's was 
0.8440 (Rank 11 of 193) and the UK's was 0.9193 (Rank 1 of 193), both of which are higher than the world average (0.4922). Regarding the e-participation score, Japan's was 0.9831 (Rank 2 of 193) and the UK's was 1.000 (essentially, the baseline), and both are again higher than the world average $(0.4625)$. Therefore, this collaborative project between Japan and the UK is about aging and super-aging societies within the context of countries that have a strong infrastructure in terms of online public services.

In Japan, according to a 2012 white paper by the Ministry of Internal Affairs and Communications [10], the rate of elderly people using the Internet has been growing ever since the survey was first administered in 2008 . Almost $60 \%$ of survey respondents aged 65-70 years old have experience with using ICT. According to e-Government initiatives in Japan, the Japanese government has promoted government informatization in terms of the electronic provision of government information and a shift to electronic application/form submission based on the Master Plan for Promoting Government-wide use of IT [11]. The opinion survey on the future of public services by the Cabinet office in 2016 stated that around $40 \%$ of Japanese respondents aged over 20 supported the computerization of public services [12]. Furthermore, the Japanese government created a vision to become an IT user society at the highest level in the world. In addition to tax returns, information services for foreign residents, and voting for local elections (e.g., for city council members), which are already set as part of an online service infrastructure, the social security and tax number system (called "My number") was started in 2016 [13]. In 2017 , its online portal site was opened, and by 2018, it became easier to access pension information, medical expenses deduction submissions, child care services information, and healthcare data sharing online. In parallel with these developments, commercial and non-commercial sectors are also creating online based services. Regarding non- 
commercial sectors, social entrepreneurs have created mobile apps by using governmental open data [14]. The commercial sector is also attempting to promote online services toward important public issues such as healthcare, transportation, energy management, etc. For example, Accenture, an ICT consulting company, collaborates with a local municipality and local university integrating different types of digital data and creating a smart city in Aizuwakamatsu where $30 \%$ of the residents are over 65 [15]. One of the Internet based services they created was on a TV screen based menu that the elderly can use for booking on-demand bus transportation, checking local community information and health monitoring.

In the UK, the Government announced in its 2015 Budget Statement that it wanted "to deliver redesigned user-friendly public services, fit for the digital age as a way of delivering efficiencies across the public sector". Whilst some national and local government services have offered an option of online service delivery for some time, they have now moved to 'digital by default', where all services are being designed and based around the GOV.UK digital platform. Tax returns, state pensions, driving licence renewals, passport renewals, benefit claims, voter registrations, and many local authority services are all migrating to delivery by the Internet. Furthermore, according to Carter, et al. [16], one of the UK e-government strategies includes sharing information with citizens and businesses to enable the innovation of new online tools and services, thereby improving productivity and efficiency and reducing waste in the public sector. At the same time as this transition to online delivery of public services, there is a growing elderly population, many of whom have either never used the Internet or use it very infrequently. A study undertaken by the UK government's Office of Communication in 2017 [17] found that $12 \%$ of adults in the UK are non-users of the internet, this increases to $35 \%$ of 
those aged $65-74$ and $47 \%$ of those aged over 75 . In terms of usage of the internet to complete government processes online, $54 \%$ of $65-74$ year olds and $66 \%$ of those over 75 years have never used the internet for this purpose, this compares with an average of $42 \%$ for the UK population as a whole. The main reason given for non-use is a preference for verbal contact or physical form-filling rather than online communication.

\section{Conceptual background}

To understand the determinants of using online public services, various studies have come up with original frameworks of human behaviour. The main focus of most of these studies has been the human perception of the technology [i.e. 18-21]. Lee and Lyu [22] broadened this focus to include the influence of human values and made a framework of values, attitude, and behaviour [23] by applying a model to test the determinants of behavioural intention related to self-service technology (SST). SSTs are technological interfaces that allow service recipients to be more involved in the creation and delivery of the service, which helps make the service transactions more accurate, convenient, and hassle-free [24]. When it comes to the relationship between humans and new technology, people typically make the decision to use a new technology on the basis of their lifestyle and so on [25]. This is similar to consumer behaviour in general as noted by Hawkins and Mothersbaugh [26] who stated that, even before people begin an information search on a product or service, they tend to have specific needs based on their lifestyle and values as a self-concept. People develop their values and subsequent lifestyles on the basis of external factors such as culture, social status, etc. and on internal factors such as learning, personality, etc. Therefore, it is important to think about the impact of such behavior on 
the intention to use online self-service technologies from the perspectives of both internal and external human perception. This paper uses the framework of perception, attitude, and behavior, as shown in Fig. 1.

\section{Attitude toward using online self-service technologies}

The topic of intention to use SST has been discussed in terms of people's perception of technology and their propensity toward using it. Based on a study by Lin and Hsieh [19] about propensity and satisfaction, it seems that personal values, especially a utilitarian attitude [22], toward the technology will have a positive effect on using SST.

In addition, there have been various studies that measure people's attitude toward technology usage such as TAM (technology acceptance model) [27] and UTAUT (the unified theory of acceptance and use of technology) [28]. Both the models primarily use the positive aspects of technology as measurement items, but people may often have difficulties and skepticism about particular technologies impacting on their use. To include an examination of the negative side of technology, Parasuraman [8] came up with the concept of a Technology Readiness Index (TRI). Technology readiness is defined as “people's propensity to embrace and use new technologies to accomplish goals in home life and at work" [8, p.308]. The scale of technology readiness is measured by four subcategories: Optimism, Innovativeness, Discomfort, and Insecurity. Optimism relates to a positive view of technology and a belief that it offers people increased control, flexibility, and efficiency in their lives, and innovativeness relates to a tendency to be a technology pioneer and thought leader. These two subcategories are the positive drivers of technology readiness. In contrast, discomfort and insecurity are the negative drivers of technology readiness. Discomfort relates to a perceived lack of control over the 
technology and a feeling of being overwhelmed by it. Insecurity relates to a distrust of the technology stemming from skepticism about its potential harmful consequences. According to Lin, et al. [29], the TRI has a relationship with both perceived usefulness and ease of use. Although the TRI was updated in 2016 to make the items easier to comprehend, the original authors stress that the new TRI "seems to preserve TRI 1.0's overall distinct dimensional structure" [30, p.70]. To obtain a firm grasp of the overall disposition towards using online self-service technology for public services, the authors of the present work have utilized the original Technology TRI by Parasuraman [8].

\section{Perception: internal aspect}

In the perception part of Fig. 1, there are two different aspects: internal and external. Regarding the internal aspect, this paper focuses on memory self-efficacy and aging satisfaction, which together represent the attitude toward aging, a fundamental internal characteristic of elderly people that may affect their willingness to access online public services. Confidence and morale in daily life might also affect elderly people's attitudes towards SST.

Self-efficacy refers to "a judgment of one's ability to organize and execute given types of performances" [31, p.21]. Since self-efficacy is reflected by social cognition, it can be brought about by encouraging people, i.e., by cheering them on. According to Ruyter and $\mathrm{Yu}$ [32], "Getting verbal or social encouragement from others helps people overcome their insecurities and instead focus on giving their best effort to accomplish a certain task" [32, p.137]. Regarding the objective of self-efficacy, it might be well-suited for conceptualizing the memory experiences of many older adults [33]. The everyday memory self-efficacy scale (EMSES) relates to the control of personal information and 
was developed by Ide and Mori [34]. The EMSES helps people have confidence in their own ability with memory and enhances the self-efficacy of elderly people. Therefore, it may encourage them to access online public services.

As personal confidence to use technology may also be influenced by one's attitude towards the aging process, this study also considers attitudes of respondents towards their own aging through the Philadelphia Geriatric Center Morale Scale [35].

\section{Perception: external aspect}

From an external perspective, attitudes towards social interaction may also affect the level of confidence in interacting online. An individual's social interaction can be examined by their perceived social support and social inhibition. Social support can be measured using the multidimensional scale of perceived social support (MSPSS) [36]. The MSPSS has three defining traits. First, it addresses the subjective assessment of social support adequacy. Second, it is designed using a scale that measures the consciousness of social support from family, friends, and significant others. Third, it is self-explanatory, simple to use, and time-conserving.

In addition to the social support factor, this study uses social inhibition to assess elderly people's attitudes toward social interaction. Social inhibition is a subcategory of the Factor Structure and Internal Consistency of the Type D Scale 14 (DS14). This scale indicates discomfort and discretion in social interaction [37].

\section{Development of hypotheses}

The effects of attitude toward aging on propensity to use technology

Research by Wagner et al. [38] suggested that as people get older, attitudes towards ICT and the Internet become more negative. This is supported by a study by Feist et al. [39] 
which showed that people aged 65-79 demonstrate strong positive attitudes towards ICT whereas people over 79 are significantly more negative. Regarding this relationship between attitude toward aging and technology readiness, both memory self-efficacy and aging satisfaction factors are considered to be positive influencers on technology readiness. Memory self-efficacy means the confidence to remember something, which reflects the memory of how to use a new technology. Memory loss can affect one's ability to navigate menu structures and retrieve information from the Internet [40,41]. According to Berry, et al. [33], "if the elderly feel competent and confident in their ability, they are more likely to engage in the task at hand and expend the effort and persistence necessary for task mastery" [33, p.702], which will be relevant to form their propensity to use a technology. In addition, since aging satisfaction also means the sense of fulfilment about a current state compared with one in the past, then its positive feeling may have a relationship with the propensity toward doing something new, including technology usage. On the other hand, such factors may also have a relationship with the negative aspect of technology readiness. On the basis of these considerations, the authors set the following hypotheses.

- H1a: Memory self-efficacy positively affects the positive aspect of technology readiness.

- H1b: Memory self-efficacy negatively affects the negative aspect of technology readiness.

- H2a: Aging satisfaction positively affects the positive aspect of technology readiness.

- H2b: Aging satisfaction negatively affects the negative aspect of technology readiness. 
The effects of perceived social support on attitude toward aging

Several previous studies have addressed the relationship between social support and attitude toward aging. Lamont, et al. [42] stated that satisfaction with social support has a positive effect on attitude toward aging. Since perceived social support includes positive interaction with others, including encouragement and cheer, it can be considered an influencer on self-efficacy [31,32]. In addition, people who are highly satisfied with their social support experience have less psychological distress [43] and lower levels of loneliness and fatigue [44]. Family-based support has a particularly strong effect on life satisfaction $[45,46]$. These findings mean that perceived social support may have a relationship with self-efficacy and aging satisfaction. Regarding social support perception, the dissatisfaction with contact with friends is strongly related to loneliness [47]. This type of mind-set for making social interaction is relevant to the concept of social inhibition, which is a negative attitude toward interaction with others. Perceived social support might have a negative relationship with social inhibition. On the basis of these findings, the authors set the following hypotheses.

- H3a: Perceived social support positively affects memory self-efficacy of the elderly.

- H3b: Perceived social support positively affects aging satisfaction of the elderly.

- H3c: Perceived social support is negatively affected by social inhibition.

\section{The effects of propensity to use a technology on actual technology usage}

This study utilizes the concept of technology readiness [8], which is often used to measure people's propensity to use a new technology. This concept can be applied to the 
understanding of all generations of human behavior, including the elderly. The authors mentioned earlier how, in terms of technology readiness, its positive side implies an enthusiasm for the technology while its negative side implies a human skepticism. Such aspects can be considered as the actual behavior of the elderly when it comes to using online public services, since online public services are considered by the elderly to be a new technology not available in their younger years and that they can now benefit from. Therefore, we can say that technologies associated with online public services are new for them, unlike the generation of digital natives. That is why it is worth testing the relationship between technology readiness and actual usage of online public services. The hypotheses are as follows.

- H4a: Positive aspect of technology readiness positively affects the actual usage of online public services.

- H4b: Negative aspect of technology readiness negatively affects the actual usage of online public services.

Thus, this study investigates the effect of both personal and social factors on the technology readiness and actual behavior of elderly people toward public online services. The conceptual model is set out in Fig. 1. 


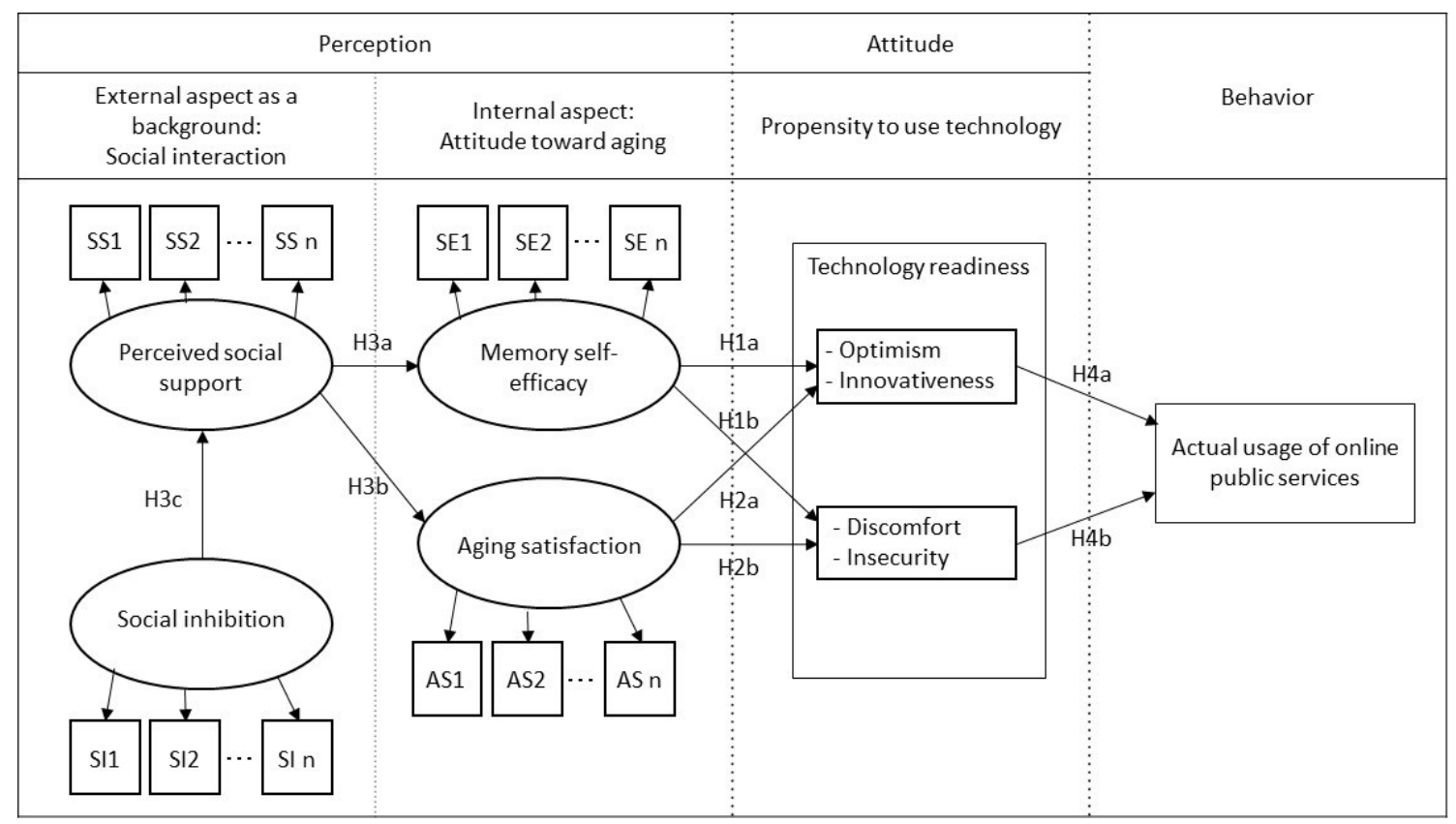

Fig. 1 Conceptual model.

\section{Methodology}

\section{Sample and data collection procedure}

Data for this study were taken from a questionnaire administered in two different locations: Japan and the UK. In Japan, the authors administered the questionnaire in Nomi city, Ishikawa prefecture. Since the target of the survey was the elderly, the authors proceeded in a structured interview style. Nomi city has a population of approximately 50,000 and is located around 40 minutes by car from Kanazawa city, the prefectural capital, which has a population of around 500,000. Therefore, Nomi city is considered a suburban area of Kanazawa city.

In terms of the data collection itself, the authors focused on an "iki-iki salon" in cooperation with the Social Welfare Council in Nomi city. "Iki-iki" means "active" in 
Japanese, and the purpose of these salons is to promote active living in the elderly by having them enjoy group activities such as exercise, hobby classes, and so on. According to the Japan Social Welfare Council's Web site [48], the definition of an iki-iki salon is "locally based friend-making activities through joint planning and managing of events between citizens and volunteer staff'. There are a variety of iki-iki salons, including those for the elderly, the disabled, and parents raising children. There are over 26,000 such salons across Japan as of 2000. The authors recruited 200 participants (aged 65+) at weekly exercise events for the elderly in a Nomi city iki-iki salon and were able to collect 182 completed questionnaires.

On the UK side, one of the authors administered a paper-based self-completion survey with 200 elderly residents (aged 65+) from the suburban districts of the city of Glasgow, Scotland. The respondents were recruited at weekly local events for the elderly related to social and educational classes. The city of Glasgow has a population of around 600,000 , and the majority of the respondents lived within a 30-40 minute journey of the city center. A total of 142 questionnaires were completed.

\section{Measurements}

The role of behavioral intention toward online public services is assessed by questions about the type of online public services accessed, the likelihood of accessing online public services in the future, and the reasons for liking or disliking online public services. We set options to measure the degree of actual usage of online public services for the following eight purposes: (1) to obtain general information on government services, (2) to receive and pay money (including pension, tax, public utilities), (3) to apply for documents (driver's license, social insurance, passports, road tax, TV license), (4) to 
prepare tax returns, (5) to book appointments for health care, meetings, interviews, etc., (6) to undertake electronic voting / complete government surveys, (7) to seek information on transportation / road conditions, etc., and (8) to arrange services / report problems relating to housing, refuse disposal, lighting, road repairs, etc. Respondents checked all of the options that they had used. We summed up the total number of items and used the results to measure the degree of actual usage of online public services. Age, gender, educational background, and family structure were also considered.

Regarding technology readiness, 12 items from TRI1.0 [8] were utilized as questionnaire items. Since these items have both positive and negative values, we divided the answers into those related to either the positive side of technology readiness or the negative side, thereby measuring the degree of propensity to use a technology.

Regarding memory self-efficacy and aging satisfaction as a potential influencer to technology readiness, we used items from the everyday memory self-efficacy scale (EMSES) by Ide and Mori [34]. We also used the Philadelphia Geriatric Center Morale Scale by Lawton [35] to understand aging satisfaction.

Regarding perceived social support as an external perception aspect, questionnaire items from the multidimensional scale of perceived social support (MSPSS) [36] were used. We also used a subcategory of the Factor Structure and Internal Consistency of the Type D Scale 14 by Denollet [37] to measure the degree of social inhibition of the elderly. All items were measured using a 5-point Likert scale anchored by "Strongly agree" and "Strongly disagree". Details are listed in Table 1.

Table 1 Questionnaire items 


\begin{tabular}{|c|c|c|}
\hline Items & & Contents \\
\hline \multirow{12}{*}{$\begin{array}{l}\text { Technology } \\
\text { readiness }\end{array}$} & \multirow{3}{*}{ Optimism } & Technology gives people more control over their daily lives. (TRI 1.0 \& 2.0) \\
\hline & & I find new technologies to be mentally stimulating. (TRI 1.0) \\
\hline & & $\begin{array}{l}\text { Products and services that use the newest technologies are much more convenient to use. (TRI } \\
1.0 \text { ) }\end{array}$ \\
\hline & \multirow{3}{*}{ Innovativeness } & I find I have fewer problems than other people in making technology work for me. (TRI 1.0) \\
\hline & & $\begin{array}{l}\text { In general, I am among the first in my circle of friends to acquire new technology when it } \\
\text { appears. (TRI } 1.0 \& 2.0 \text { ) }\end{array}$ \\
\hline & & $\begin{array}{l}\text { I can usually figure out new high-tech products and services without help from others. (TRI } \\
1.0 \& 2.0)\end{array}$ \\
\hline & \multirow{3}{*}{ Discomfort } & $\begin{array}{l}\text { Sometimes, I think that technology systems are not designed for use by ordinary people. (TRI } \\
1.0 \& 2.0 \text { ) }\end{array}$ \\
\hline & & $\begin{array}{l}\text { There is no such thing as a manual for a high-tech product or service that's written in plain } \\
\text { language. (TRI } 1.0 \& 2.0 \text { ) }\end{array}$ \\
\hline & & $\begin{array}{l}\text { Many new technologies have health or safety risks that are not discovered until after people } \\
\text { have used them. (TRI 1.0) }\end{array}$ \\
\hline & \multirow{3}{*}{ Insecurity } & $\begin{array}{l}\text { I don't feel confident doing business with a place that can only be reached online. (TRI } 1.0 \& \text { \& } \\
2.0 \text {. }\end{array}$ \\
\hline & & I worry that information I send over the Internet will be seen by other people. (TRI 1.0) \\
\hline & & $\begin{array}{l}\text { Whenever something gets automated, I need to check carefully that the machine or computer } \\
\text { is not making mistakes. (TRI 1.0) }\end{array}$ \\
\hline \multirow{9}{*}{$\begin{array}{l}\text { Internal } \\
\text { factors }\end{array}$} & \multirow{5}{*}{ Self-efficacy } & I can remember my shopping list. \\
\hline & & I can remember promises. \\
\hline & & I can remember words during conversations. \\
\hline & & I don't forget to pay a bill on time. \\
\hline & & I don't forget what I want to do. \\
\hline & \multirow{4}{*}{$\begin{array}{l}\text { Aging } \\
\text { satisfaction }\end{array}$} & Things keep getting worse as I get older. (-) \\
\hline & & I have as much pep as I had last year. \\
\hline & & As I get older, I am less useful. $(-)$ \\
\hline & & I am as happy now as I was when I was younger. \\
\hline \multirow{10}{*}{$\begin{array}{l}\text { External } \\
\text { factors }\end{array}$} & \multirow{5}{*}{ Social inhibition } & I often feel inhibited in social interactions. \\
\hline & & I find it hard to start a conversation. \\
\hline & & I am more of an introvert than an extrovert. \\
\hline & & I often talk to strangers. \\
\hline & & I would rather keep other people at a distance. \\
\hline & \multirow{5}{*}{ Social support } & There is a special person who is around when I am in need. \\
\hline & & There is a special person with whom I can share my joys and sorrows. \\
\hline & & I have a special person who is a real source of comfort to me. \\
\hline & & My friends really try to help me. \\
\hline & & My family really tries to help me. \\
\hline
\end{tabular}

\section{Analysis}

First, we performed a descriptive analysis to determine the characteristics of the data. Then, to test our hypotheses on the research framework (shown in Fig. 1), we performed structural equation modelling analysis by using SPSS Amos 22 software. This method is useful for understanding the relationship between factors that cannot be observed directly. Before proceeding with the methodology, we checked the inner consistency of the technology readiness index to sum up the items by using Cronbach's alpha as well as average variance extracted and composite reliability. 
We also utilized the following three frequently used measures: (1) the goodness of fit index (GFI), which checks for sample size effects; (2) the root mean-squared error of approximation (RMSEA), which measures population discrepancy per degree of freedom; and (3) the comparative fit index (CFI), which checks for non-normal distributions [18].

\section{Results}

The characteristics of the data are shown in Table 2. Most respondents were female and most of the Japanese respondents were over 75 years old compared with those in the UK, who were a little younger. Regarding educational background, none of the respondents in Japan had any education higher than a master's degree. In terms of family structure, most of the respondents from Japan lived with others, including their spouse, children, and so on, while more of the respondents in the UK lived alone. Confirmatory factor analysis was performed to test the validity of the measurement model, which included four latent variables: perceived social support, memory self-efficacy, aging satisfaction, and social inhibition (listed in Table 3). Some items were removed from the model because they yielded low factor loadings. The structural equation model had a reasonable fit to the data in both countries: $\chi^{2}(203)=366.337, \mathrm{p}<.001 ; \chi^{2} / \mathrm{df}=1.805 ; \mathrm{CFI}=.721 ; \mathrm{GFI}=.848$; RMSEA $=.067$ in Japan and $\chi^{2}(129)=307.523, \mathrm{p}<.001 ; \chi^{2} / \mathrm{df}=2.384 ; \mathrm{CFI}=.758 ;$ GFI $=.821 ; \mathrm{RMSEA}=.099$ in the UK.

Table 2 Demographic characteristics

JP UK 


\begin{tabular}{lcccc}
\cline { 2 - 4 } & Frequency & $\begin{array}{c}\text { Valid } \\
\text { percentage }\end{array}$ & Frequency & $\begin{array}{c}\text { Valid } \\
\text { percentage }\end{array}$ \\
\hline Gender & 41 & 22.5 & 49 & 34.5 \\
Male & 141 & 77.5 & 93 & 65.5 \\
Female & & & & \\
Age & 40 & 22.0 & 59 & 41.5 \\
$65-69$ & 43 & 23.6 & 40 & 28.2 \\
$70-74$ & 43 & 23.6 & 26 & 18.3 \\
$75-79$ & 56 & 30.8 & 17 & 12.0 \\
$80+$ & & & & \\
& & & & \\
Education & 165 & 90.7 & 27 & 19.0 \\
Junior and high school & 17 & 9.3 & 37 & 26.1 \\
Bachelor's degree & 0 & 0 & 55 & 38.7 \\
Master's degree & 0 & 0 & 23 & 16.2 \\
Doctoral degree & & & & \\
Family structure & 16 & 8.8 & 54 & 38.0 \\
Live alone & 166 & 91.2 & 88 & 62.0 \\
Live with somebody & & &
\end{tabular}

Table 3 Confirmative factor analysis

\begin{tabular}{|c|c|c|}
\hline Constructs and items & $\begin{array}{c}\mathrm{JP} \\
(\mathrm{n}=182)\end{array}$ & $\begin{array}{c}\text { UK } \\
(n=142)\end{array}$ \\
\hline \multicolumn{3}{|l|}{ Positive aspect of technology readiness (JP: $\alpha=.704, \mathrm{AVE}=.408, \mathrm{CR}=.804 ; \mathrm{UK}: \alpha=.842, \mathrm{AVE}=.560, \mathrm{CR}=.884)$} \\
\hline Technology gives people more control over their daily lives. & .506 & 677 \\
\hline I find new technologies to be mentally stimulating. & .703 & .769 \\
\hline Products and services that use the newest technologies are much more convenient to use. & .662 & .681 \\
\hline I find I have fewer problems than other people in making technology work for me. & .650 & .784 \\
\hline In general, I am among the first in my circle of friends to acquire new technology when it appears. & .682 & .793 \\
\hline I can usually figure out new high-tech products and services without help from others. & .609 & .775 \\
\hline \multicolumn{3}{|l|}{ Negative aspect of technology readiness $(\mathrm{JP}: \alpha=.661, \mathrm{AVE}=.372, \mathrm{CR}=.780 ; \mathrm{UK}: \alpha=.731, \mathrm{AVE}=.432, \mathrm{CR}=.818)$} \\
\hline Sometimes, I think that technology systems are not designed for use by ordinary people. & .564 & .684 \\
\hline There is no such thing as a manual for a high-tech product or service that's written in plain language. & .582 & .514 \\
\hline $\begin{array}{l}\text { Many new technologies have health or safety risks that are not discovered until after people have used } \\
\text { them. }\end{array}$ & 612 & .591 \\
\hline I don't feel confident doing business with a place that can only be reached online. & .598 & .694 \\
\hline I worry that information I send over the Internet will be seen by other people. & .630 & .728 \\
\hline $\begin{array}{l}\text { Whenever something gets automated, I need to check carefully that the machine or computer is not } \\
\text { making mistakes. }\end{array}$ & .669 & .708 \\
\hline
\end{tabular}

The results of the hypotheses tests are summarized in Table 4. The results of H1a and $\mathrm{H} 1 \mathrm{~b}$, which speculated that memory self-efficacy would positively affect the positive side of technology readiness and negatively affect the negative side of technology readiness, indicate that memory self-efficacy is not a significant predictor of the positive side of technology readiness in either Japan $(\beta=.047$, n.s. $)$ or the UK $(\beta=-.040$, n.s. $)$. On the other hand, memory self-efficacy is a significant positive predictor of the negative side of technology readiness in Japan $(\beta=.270, p<.01)$. 
The results of $\mathrm{H} 2 \mathrm{a}$ and $\mathrm{H} 2 \mathrm{~b}$, which speculated that aging satisfaction would positively affect the positive side of technology readiness and negatively affect the negative aspect of technology readiness, indicate that aging satisfaction is a significant positive predictor of the positive side of technology readiness in the UK $(\beta=.221, p<.05)$ but not in Japan $(\beta=.097$, n.s. $)$. Regarding the relationship with the negative side of technology readiness, aging satisfaction is a significant negative predictor of the negative side of technology readiness in both Japan $(\beta=-.209, \mathrm{p}<.10)$ and the UK $(\beta=-.296, \mathrm{p}<.01)$.

The results for $\mathrm{H} 3 \mathrm{a}$ and $\mathrm{H} 3 \mathrm{~b}$, which speculated that perceived social support would positively affect the memory self-efficacy and aging satisfaction, indicate that perceived social support is a significant positive predictor of both memory self-efficacy $(\beta=.507, \mathrm{p}<.001)$ and aging satisfaction $(\beta=.542, \mathrm{p}<.01)$ in Japan, while perceived social support is a significant positive predictor of only aging satisfaction $(\beta=.422, p<.001)$ in the UK. The results for $\mathrm{H} 3 \mathrm{c}$, which speculated that social inhibition would negatively affect perceived social support, indicate that social inhibition is a significant negative predictor of perceived social support in both Japan $(\beta=.430, p<.01)$ and the UK $(\beta=.296$, $\mathrm{p}<.01)$.

The results of $\mathrm{H} 4 \mathrm{a}$, which speculated that the positive side of technology readiness would positively promote the actual usage of online public self-service technologies, and of $\mathrm{H} 4 \mathrm{~b}$, which speculated that the negative side of technology readiness would negatively affect the actual usage of online public self-service technologies, indicate that the positive side of technology readiness is a significant positive predictor of actual usage of online public self-service technologies in the UK $(\beta=.480, p<.001)$ but not in Japan $(\beta=.314$, n.s. $)$. Regarding $H 4 b$, the result shows that the negative side of technology readiness is a negative significant predictor of the effect on actual usage of 
online public self-service technologies in both Japan $(\beta=-.114, p<.10)$ and the UK $(ß=-.158, \mathrm{p}<.05)$.

Table $4 \quad$ Summary of support for hypotheses

\begin{tabular}{|c|c|c|c|c|c|c|c|}
\hline \multirow{2}{*}{\multicolumn{4}{|c|}{ Hypothesized paths }} & \multicolumn{2}{|c|}{ JP } & \multicolumn{2}{|c|}{ UK } \\
\hline & & & & \multicolumn{2}{|c|}{ Supported } & \multirow{2}{*}{\begin{tabular}{|l} 
S.E. \\
-.040
\end{tabular}} & \multirow{2}{*}{$\frac{\text { Supported }}{\text { No }}$} \\
\hline \multirow{2}{*}{\multicolumn{2}{|c|}{$\begin{array}{l}\text { H1a: } \quad \text { Memory self-efficacy } \\
\text { H1b: }\end{array}$}} & $\rightarrow$ & Positive TR & .047 & No & & \\
\hline & & $\rightarrow$ & Negative TR & $.270^{* *}$ & No & .139 & No \\
\hline \multirow{2}{*}{\multicolumn{2}{|c|}{$\begin{array}{l}\mathrm{H} 2 \mathrm{a} \\
\mathrm{H} 2 \mathrm{~b}\end{array}$}} & $\rightarrow$ & Positive TR & .097 & No & $.221 *$ & Yes \\
\hline $\mathrm{H} 2 \mathrm{~b}$ & & $\rightarrow$ & Negative TR & $-.209+$ & $\begin{array}{l}\text { Weakly } \\
\text { Yes }\end{array}$ & $-.296^{* *}$ & Yes \\
\hline \multirow{3}{*}{$\begin{array}{l}\text { H3a: } \\
\text { H3b: } \\
\text { H3c: }\end{array}$} & \multirow[t]{2}{*}{ Perceived social support } & $\rightarrow$ & Memory self-efficacy & $.507 * * *$ & Yes & .037 & No \\
\hline & & $\rightarrow$ & Aging satisfaction & $.542 * *$ & Yes & $.422 * * *$ & Yes \\
\hline & $\begin{array}{l}\text { Social inhibition: } r \text {-check } \\
\text { Positive TR }\end{array}$ & $\rightarrow$ & Perceived social support & $-.430 * *$ & Yes & $-.296^{* *}$ & Yes \\
\hline \multirow{2}{*}{$\begin{array}{l}\mathrm{H} 4 \mathrm{a} \\
\mathrm{H} 4 \mathrm{~b}\end{array}$} & \multirow{2}{*}{ Negative TR } & $\rightarrow$ & SST behavior & .314 & No & $.480^{* * *}$ & Yes \\
\hline & & $\rightarrow$ & SST behavior & $-.114+$ & $\begin{array}{l}\text { Weakly } \\
\text { Yes }\end{array}$ & $-.158 *$ & Yes \\
\hline
\end{tabular}

\section{Discussion}

The aim of this study was to identify the effect of the personal beliefs of the elderly on their attitude toward using online public services and discuss the social policy implications for improving the elderly's intention to use ICT. After examining the existing literature, we conclude that research on the relationship between aging-specific attitudes and propensity to use new technologies is limited.

As for the results of this study, in $\mathrm{H} 1 \mathrm{a}, \mathrm{H} 1 \mathrm{~b}, \mathrm{H} 2 \mathrm{a}$, and $\mathrm{H} 2 \mathrm{~b}$ the authors examined perspectives of "self-efficacy" versus "satisfaction" to understand how these factors affect technology readiness. On the basis of the questionnaire responses, it seems that memory self-efficacy as one of the influencers of self-efficacy for the elderly does not have any specific meaning for technology readiness, while aging satisfaction does have some meaning. Memory self-efficacy was measured as an evaluation of current ability to memorize something while aging satisfaction was measured by the items in which the elderly were asked to judge their current status compared with past times. By combining 
both results, the issue of how the elderly evaluate themselves is generated. For example, the elderly might have an attitude toward technology usage that is not based on the recognition of just their current state but also on a composite feeling that consists of a comparison between their current state and past state. According to Moschis [49], "the lower the older person's cognitive or subjective age, in relation to his or her chronological age, the greater is their propensity to use products and services designed to maintain a youthful image" [49, p.197]. Therefore, as a practical implication of this finding, the authors suggest that it is important to socially encourage the elderly to make themselves feel more "youthful" by motivating them to minimize the gap between their current ability and their perceptions of their past ability. It is true that people's physical ability in general decreases as they age, but the important thing is for them to focus on other aspects of life that have not decreased.

Regarding the results of $\mathrm{H} 3 \mathrm{a}, \mathrm{H} 3 \mathrm{~b}$, and $\mathrm{H} 3 \mathrm{c}$, the authors suggest that satisfaction of the elderly with their aging is influenced by the degree of their sense of positive relationships with others and is negatively influenced by social inhibition. The results of $\mathrm{H} 3 \mathrm{~b}$ indicate that perceived social support positively affects aging satisfaction in both Japan and the UK. This implies that life satisfaction related to aging can be improved by the perception of the existence of the individual having important persons in their lives. However, the results of $\mathrm{H} 3 \mathrm{a}$ show that only in Japan does perceived social support improve memory self-efficacy. In general, encouragement from others is one of the determinants of improving self-efficacy [31]. That implies there may be some condition providing a feeling of coexistence and an intersubjective belief in one's ability, thereby promoting one's confidence to be able to do something. In Japan, familial relations may reflect the collectivist nature of their society, with members of a family being expected to 
work towards the betterment of the family rather than the individual. In contrast, in the UK, we might consider that the wider geographical dispersal of families may result in social support stemming more from families linked by telecommunications and the Internet, which makes it difficult to share a feeling of coexistence. The results of H3a and $\mathrm{H} 3 \mathrm{~b}$ suggest the importance of creating physical opportunities to cultivate the feeling of coexistence with others and potentially reduce loneliness and isolation.

The results demonstrate that the technology readiness factors are partly associated with the actual usage of online public services, especially in the UK, but at the same time, technology readiness factors are not necessarily the determinant for the elderly. Considering the results of the Japan data, H4a was not supported as strongly as H4b. In terms of online services, many service providers including not only the private sector but also the public sector are nowadays trying to collect personal data from citizens as customers. Therefore, trust about how personal data is dealt with will also affect technology readiness and actual usage of technology. Our findings support this aspect with the results of $\mathrm{H} 4 \mathrm{~b}$. The negative aspect of technology readiness was a significant predictor of actual usage of online public services. However, the significance of the result differed depending on the culture. According to a recent survey about consumer attitudes using data for 900 people in five countries - the US, the UK, Germany, China, and India-by Morey, et al. [50], 97\% of the people surveyed expressed concern that businesses and the government might misuse their data. Online services need personal data in order to provide better services but identity theft was a top concern, although the extent of this varies by country. Regarding trustworthy organizations that handle personal information responsibly, the survey ranked governments as number 10 out of 12 organization types. This result implies that people do not necessarily trust their 
government to handle personal data. A number of studies have shown that older adults fear using ICT and the Internet as it may have a negative effect on their privacy and personal security [51-53]. Morey, et al. [50] also conclude that there may be fundamental dissimilarities among cultures. For example, the UK and the US are quite individualistic, which accounts for their citizens' stronger feelings about personal information compared with Asian countries such as China and India.

Based on the discussions above, there are two potential directions to consider with regards social policy addressing ICT and the elderly. The first relates to motivating the elderly to use new technology by influencing their attitudes towards personal youthfulness and self-efficacy. This can be encouraged through social policies regarding lifelong education as this has the potential to enable the elderly to develop not only ICT skills [54] but also greater youthfulness or juvenescence [55]. Education may also assist in maintaining their intellectual curiosity to learn something new as well as improve their employability in a later career (e.g. [56,57]). According to the survey of consumption disparities in digital devices in Finland [58], there is a clear relationship between education level and the consumption of new digital technologies.

The other direction relates to improved preparation for the future development of online public services. Social policy related to the introduction of IT for public service delivery must consider the true needs of the elderly in terms of customer delight and loyalty, which may lead to the continuous usage of self-service technology [4].

There is a need to consider the obstacles to accessing ICT [59] and empowering the elderly (e.g. [60]). The involvement of the elderly in co-creating services [61] should be considered in order to reduce social exclusion [62] in ICT adoption. The concept of exclusion in digital technologies such as the Internet has often been described as the 
digital divide. There are two kinds of divide; the first order divide is about inequality in accessing ICT and the other is about inequality in the ability to use ICT [63]. Although Internet access is strongly correlated with various socio-demographic dimensions such as income and education, this first order digital divide is on the verge of being overcome in many developed countries [64]. Therefore, the more critical aspect going forward is the second order digital divide. Mervyn, et al. [65] indicates there is a connection between complex information needs and social exclusion. The more complex online public services become, the more barriers there will be to the elderlies' ability to use it reinforcing their exclusion. The public sector can potentially learn about reducing complexity from examples in the private sector. For example research on online banking demonstrates the importance of web design to ease form filling potentially easing the task for the elderly [66]. There is a need for human intermediaries to help socially excluded people understand how to use IT services. Policy makers need to focus more on activating the efforts of people who directly communicate with the elderly such as social workers and family members. Encouraging inter-generational support from younger tech-savvy individuals may also impact positively on the elderly's perceptions of trust in technology which is crucially important to the future growth of online public service usage.

\section{Conclusion}

The aim of this study was to identify the impact of the elderly's personal beliefs on their attitude toward using online public services. This study proposes a framework that describes the impact of the internal and external personal characteristics of elderly people on their capability to access online public services. Questionnaires were administered to 
the elderly $(65+$ years old $)$ in Japan and the UK, countries that have a well-developed online public services infrastructure but have an increasingly aging society. We found that aging satisfaction is the strongest factor in terms of promoting online public services usage, and that it is enhanced by the existence of family and friends combined with social interaction.

This study could be an essential starting point in the critical discourse of how online public services should be developed in a manner that engages with the elderly, which is a key requirement if technology is going to foster a good society [5]. Our findings suggest that governments need to understand how the aging satisfaction of the elderly impacts on their use of online public services. There are many ways to promote aging satisfaction through the local community, private companies, public services, not for profit organizations, and even the family, but the important thing is to encourage confidence in an individual's current abilities. In addition, technology readiness in itself may not necessarily become the most significant predictor of online public service usage as cultural background and the level of trust associated with the management of personal data may have a bigger influence. Governments in rolling out their online services may also need to better identify which members of the elderly population are able and willing to use the Internet and which are isolated and excluded from this delivery channel. There may then be a need for support or alternative delivery mechanisms to be introduced and targeted at this second grouping.

Funding: This work was supported by a grant from the Daiwa Anglo Japanese Foundation. 
References

[1] M.-H. Li, M.K. Feeney, Adoption of Electronic Technologies in Local U.S. Governments, Am. Rev. Public Adm. 44 (2014) 75-91. doi:doi:10.1177/0275074012460910.

[2] L. Torres, V. Pina, B. Acerete, E-government developments on delivering public services among EU cities, Gov. Inf. Q. 22 (2005) 217-238. doi:http://dx.doi.org/10.1016/j.giq.2005.02.004.

[3] J. Wirtz, C. Lovelock, Services Marketing: People, Technology, Strategy Eighth Edition, World Scientific Publishing Company, n.d. https://books.google.co.jp/books?id=dKJIDQAAQBAJ.

[4] Charla Griffy-Brown, M. Chun, H. Koeppel, Using Customer-Facing Technology to Create New Business Value: Insight from the Public and Private Sector into the Changing Value Equation, J. Technol. Manag. Grow. Econ. 2 (2011) 21-33.

[5] Charla Griffy-Brown, Brian D. Earp, Omar Rosas, Technology and the good society, Technol. Soc. 52 (2018) 1-3. doi:10.1016/J.TECHSOC.2018.01.001.

[6] T. Heart, E. Kalderon, Older adults: Are they ready to adopt health-related ICT?, Int. J. Med. Inform. 82 (2013) e209-e231. doi:http://dx.doi.org/10.1016/j.ijmedinf.2011.03.002.

[7] J. Powell, The social and economic forces of global ageing in a global society, J. Comp. Soc. Welf. 28 (2012) 165-177.

[8] A. Parasuraman, Technology Readiness Index (Tri), J. Serv. Res. 2 (2000) 307320. doi:doi:10.1177/109467050024001. 
[9] United Nations, E-Government development index, 2017 (2016).

https://publicadministration.un.org/egovkb/en-us/About/Overview/-E-

Government.

[10] J. Ministry of Internal Affairs and Communications, Information and communications in Japan, White Paper 2013, Ministry of Internal Affairs and Communications, Japan, 2013.

http://www.soumu.go.jp/johotsusintokei/whitepaper/eng/WP2013/2013index.html.

[11] Ministry of Internal Affairs and Communications, Japans's e-Government initiatives, (n.d.). http://www.e-gov.go.jp/en/e-government.html (accessed September 10, 2019).

[12] The Cabinet office, Abstract of the opinion survey on the future of public services, (2016) 1-18. https://survey.gov-online.go.jp/h27/h27koukyou/gairyaku.pdf (accessed September 10, 2019).

[13] Cabinet Secretariat, The social security and tax number system, 2017 (2016). http://www.cas.go.jp/jp/seisaku/bangoseido/english.html.

[14] R.E. Sieber, P.A. Johnson, Civic open data at a crossroads: Dominant models and current challenges, Gov. Inf. Q. 32 (2015) 308-315. doi:https://doi.org/10.1016/j.giq.2015.05.003.

[15] G. Trencher, A. Karvonen, Innovating for an aging society: insights from two Japanese smart cities, in: A. Karvonen, F. Cugurullo, F. Caprotti (Eds.), Insid. Smart Cities Place, Polit. Urban Innov., Routledge, London, 2018.

[16] L. Carter, V. Weerakkody, B. Phillips, Y.K. Dwivedi, Citizen Adoption of EGovernment Services: Exploring Citizen Perceptions of Online Services in the 
United States and United Kingdom, Inf. Syst. Manag. 33 (2016) 124-140. doi:10.1080/10580530.2016.1155948.

[17] Ofcom, Adult's Media Use and Attitudes Report, (n.d.). www.ofcom.org.uk/_data/assets/pdf_file/0011/113222/Adults-Media-Use-andAttitudes-Report-2018.pdf (accessed April 25, 2018).

[18] K. Eriksson, D. Nilsson, Determinants of the continued use of self-service technology: The case of Internet banking, Technovation. 27 (2007) 159-167. doi:http://dx.doi.org/10.1016/j.technovation.2006.11.001.

[19] J.-S.C. Lin, P.-L. Hsieh, The influence of technology readiness on satisfaction and behavioral intentions toward self-service technologies, Comput. Human Behav. 23 (2007) 1597-1615. doi:http://dx.doi.org/10.1016/j.chb.2005.07.006.

[20] J.-S.C. Lin, P.-L. Hsieh, Assessing the Self-service Technology Encounters: Development and Validation of SSTQUAL Scale, J. Retail. 87 (2011) 194-206. doi:http://dx.doi.org/10.1016/j.jretai.2011.02.006.

[21] M. Blut, C. Wang, K. Schoefer, Factors Influencing the Acceptance of SelfService Technologies, J. Serv. Res. 19 (2016) 396-416. doi:doi:10.1177/1094670516662352.

[22] H.-J. Lee, J. Lyu, Personal values as determinants of intentions to use self-service technology in retailing, Comput. Human Behav. 60 (2016) 322-332. doi:http://dx.doi.org/10.1016/j.chb.2016.02.051.

[23] P.M. Homer, L.R. Kahle, A Structural Equation Test of the Value-AttitudeBehavior Hierarchy, J. Pers. Soc. Psychol. 54 (1988) 638-646.

[24] Matthew L. Meuter, Amy L. Ostrom, Robert I. Roundtree, M.J. Bitner, SelfService Technologies: Understanding Customer Satisfaction with Technology- 
Based Service Encounters, J. Mark. 64 (2000) 50-64.

doi:10.1509/jmkg.64.3.50.18024.

[25] S. Vannoy, P. Palvia, The Social Influence Model of Technology Adoption, 2010. doi:10.1145/1743546.1743585.

[26] D.I. Hawkins, D.L. Mothersbaugh, Consumer behavior: building marketing strategy -11th edition-, McGraw-Hill/Irwin, 2010.

[27] F.D. Davis, R.P. Bagozzi, P.R. Warshaw, User acceptance of computer technology: a comparison of two theoretical models, Manag. Sci. 35 (1989) 9821003. doi:10.1287/mnsc.35.8.982.

[28] V. Venkatesh, J.Y.L. Thong, X. Xu, Consumer Acceptance and Use of Information Technology: Extending the Unified Theory of Acceptance and Use of Technology, MIS Q. 36 (2012) 157-178.

[29] C.-H. Lin, H.-Y. Shih, P.J. Sher, Integrating technology readiness into technology acceptance: The TRAM model, Psychol. Mark. 24 (2007) 641-657. doi:10.1002/mar.20177.

[30] A. Parasuraman, C.L. Colby, An updated and streamlined technology readiness index : TRI 2.0, J. Serv. Res. JSR. 18 (2015) 59-74.

[31] A. Bandura, Self-efficacy: the exercise of control, W.H. Freeman and Company, New York, 1997.

[32] K. de Ruyter, T. Yu, If you can if you think you can: the impact of customer and employee efficacy on technology-based service delivery, in: R.P. Fisk, R. Russell-Bennett, L.C. Harris (Eds.), Serv. Cust. Glob. Serv. Mark. Perspect., Tilde Publishing and Distribution, Australia, 2013. 
[33] J.M. Berry, R.L. West, D.M. Dennehey, Reliability and validity of the memory self-efficacy questionnaire, Dev. Psychol. 25 (1989) 701-713.

[34] S. Ide, N. Mori, Developing the Everyday Memory Self-Efficacy Scale (EMSES) and Testing Its Validity with Constructs Analysis，老年看護学 日本老年看護 学会誌Ｊ. Japan Acad. Gerontol. Nurs. 8 (2004) 44-53. http://ci.nii.ac.jp/naid/110007454898/en/.

[35] P.M. Lawton, The philadelphia geriatric center morale scale: a revision, J. Geontology. 30 (1975) 85-89.

[36] G.D. Zimet, N.W. Dahlem, S.G. Zimet, G.K. Farley, The Multidimensional Scale of Perceived Social Support, J. Pers. Assess. 52 (1988) 30-41. doi:10.1207/s15327752jpa5201_2.

[37] J. Denollet, DS14: Standard Assessment of Negative Affectivity, Social Inhibition, and Type D Personality, Psychosom. Med. 67 (2005) 89-97. http://journals.lww.com/psychosomaticmedicine/Fulltext/2005/01000/DS14_Sta ndard_Assessment_of_Negative_Affectivity,.13.aspx.

[38] N. Wagner, K. Hassanein, M. Head, Computer use by older adults: A multidisciplinary review, Comput. Human Behav. 26 (2010) 870-882. doi:10.1016/J.CHB.2010.03.029.

[39] H. Feist, K. Parker, N. Howard, G. Hugo, New Technologies: Their Potential Role in Linking Rural Older People to Community, Int. J. Emerg. Technol. Soc. $8(2010) 68-84$.

[40] B.J. Avolio, W.L. Gardner, Authentic leadership development: Getting to the root of positive forms of leadership, Leadersh. Q. 16 (2005) 315-338. doi:https://doi.org/10.1016/j.leaqua.2005.03.001. 
[41] I. Hardill, C.W. Olphert, Staying connected: Exploring mobile phone use amongst older adults in the UK, Geoforum. 43 (2012) 1306-1312. doi:https://doi.org/10.1016/j.geoforum.2012.03.016.

[42] R.A. Lamont, S.M. Nelis, C. Quinn, L. Clare, Social Support and Attitudes to Aging in Later Life, Int. J. Aging Hum. Dev. 84 (2016) 109-125. doi:10.1177/0091415016668351.

[43] R. Nemeroff, E. Midlarsky, J.F. Meyer, Relationships among Social Support, Perceived Control, and Psychological Distress in Late Life, Int. J. Aging Hum. Dev. 71 (2010) 69-82. doi:doi:10.2190/AG.71.1.d.

[44] K.H. Kwag, P. Martin, D. Russell, W. Franke, M. Kohut, The Impact of Perceived Stress, Social Support, and Home-Based Physical Activity on Mental Health among Older Adults, Int. J. Aging Hum. Dev. 72 (2011) 137-154. doi:doi:10.2190/AG.72.2.c.

[45] Y. Shen, D.E. Yeatts, Social Support and Life Satisfaction among Older Adults in China: Family-Based Support versus Community-Based Support, Int. J. Aging Hum. Dev. 77 (2013) 189-209. doi:doi:10.2190/AG.77.3.b.

[46] H.N. Chalise, I. Kai, T. Saito, Social Support and its Correlation with Loneliness: A Cross-Cultural Study of Nepalese Older Adults, Int. J. Aging Hum. Dev. 71 (2010) 115-138. doi:doi:10.2190/AG.71.2.b.

[47] M. Nicolaisen, K. Thorsen, What Are Friends for? Friendships and Loneliness Over the Lifespan—From 18 to 79 Years, Int. J. Aging Hum. Dev. 84 (2017) 126-158. doi:doi:10.1177/0091415016655166.

[48] Japan Social Welfare Council, About Fureai Ikiiki salon, 2017 (2000). https://www.zcwvc.net. 
[49] G.P. Moschis, Consumer Behavior in Later Life: Multidisciplinary Contributions and Implications for Research, J. Acad. Mark. Sci. 22 (1994) 195-204. doi:doi:10.1177/0092070394223001.

[50] T. Morey, T. Forbath, A. Schoop, Customer data: designing for transparency and trust, Harv. Bus. Rev. May (2015) 96-105.

[51] D. Wright, K. Wadhwa, Mainstreaming the e-excluded in Europe: strategies, good practices and some ethical issues, Ethics Inf. Technol. 12 (2010) 139-156. doi:10.1007/s10676-009-9213-y.

[52] K. Leppel, D.W. McCloskey, A cross- generational examination of electronic commerce adoption, J. Consum. Mark. 28 (2011) 261-268. doi:10.1108/07363761111143150.

[53] M. Mason, D. Sinclair, C. Berry, Nudge or Compel? Can behavioural economics tackle the digital exclusion of older people, Int. Longev. Cent. UK. Retrieved from Http//Www. Ilk. Org. Uk. (2012).

[54] D. Taylor, G. Packham, Social Inclusion through ICT: Identifying and Overcoming Barriers to ICT Use, Strateg. Chang. 25 (2016) 45-60. doi:10.1002/jsc.2046.

[55] R.P. Harrison, Juvenescence: A Cultural History of Our Age, Univ of Chicago Pr (T), 2014

[56] E. Luppi, Education in old age: An exploratory study, Int. J. Lifelong Educ. 28 (2009) 241-276. doi:10.1080/02601370902757125.

[57] Y. Li, A. Perkins, The impact of technological developments on the daily life of the elderly, Technol. Soc. 29 (2007) 361-368. doi:https://doi.org/10.1016/j.techsoc.2007.04.004. 
[58] P. Rasanen, Consumption disparities in information society: Comparing the traditional and digital divides in Finland, Int. J. Sociol. Soc. Policy. 26 (2006) 48-62. doi:doi:10.1108/01443330610644425.

[59] N. Selwyn, "E-stablishing” an Inclusive Society? Technology, Social Exclusion and UK Government Policy Making, J. Soc. Policy. 31 (2002) 1-20. doi:10.1017/S0047279402006487.

[60] M. Hardey, B. Loader, The Informatization of Welfare: Older People and the Role of Digital Services, Br. J. Soc. Work. 39 (2009) 657-669. doi:10.1093/bjsw/bcp024.

[61] R.F. Lusch, S.L. Vargo, Service-Dominant Logic: Premises, Perspectives, Possibilities, Cambridge, 2014.

[62] W. Van Winden, The End of Social Exclusion? On Information Technology Policy as a Key to Social Inclusion in Large European Cities, Reg. Stud. 35 (2001) 861-877. doi:10.1080/00343400120090275.

[63] S. Dewan, F.J. Riggins, The Digital Divide: Current and Future Research Directions, J. Assoc. Inf. Syst. 6 (2005) 298-337.

[64] T.N. Friemel, The digital divide has grown old: Determinants of a digital divide among seniors, New Media Soc. 18 (2016) 313-331. doi: $10.1177 / 1461444814538648$.

[65] K. Mervyn, A. Simon, D.K. Allen, Digital inclusion and social inclusion: a tale of two cities, Information, Commun. Soc. 17 (2014) 1086-1104. doi:10.1080/1369118X.2013.877952. 
[66] J. Arenas Gaitán, B. Peral Peral, M.. Ramón Jerónimo, Elderly and Internet Banking: An Application of UTAUT2, J. Internet Bank. Commer. 20 (2015) 123. 